\title{
On Chinese EFL Learners' Homonym Processing in Relation to Their Organization of L2 Mental Lexicon
}

\author{
Xiumei Yu (Corresponding author) \\ Department of Foreign Language, School of Humanities and Social Science \\ University of Science and Technology of China, No. 96 Jinzhai Road, Hefei 230026, Anhui, China \\ E-mail: yuxiumei@mail.ustc.edu.cn \\ Zhenyu Xu \\ Department of Foreign Languages, University of Science and Technology of China \\ East Campus of USTC, No. 96 Jinzhai Road, Hefei 230026, Anhui, China \\ Tel: 86-551-215-8199 E-mail: zyhsu@ustc.edu.cn \\ Lan Sun \\ Professor, Department of Foreign Language, School of Humanities and Social Science \\ University of Science and Technology of China, No. 96 Jinzhai Road, Hefei 230026, Anhui, China \\ Tel: 86-551-342-3397Ｅ-mail: 1sun@ustc.edu.cn
}

Received: February 15, $2011 \quad$ Accepted: April 7, $2011 \quad$ doi:10.5539/ijel.v1n2p40

\begin{abstract}
Based on the models of lexical ambiguity resolution and the organization of L2 mental lexicon proposed by previous researchers in recent years, this paper aimed at investigating the correlation between the Chinese EFL learners' homonym processing in relation to their organization of L2 mental lexicon through cross-modal sentence-priming lexical decision tasks and word association tasks completed by both English major and non-English major students. The results showed that there is a positive correlation between the learners' organization of L2 mental lexicon and their performance on English homonym processing. Inferential statistic analysis indicates that learners whose L2 mental lexicon is more syntagmatically related can process the English homonym more effectively. They can use contextual cues (semantic and syntactic information) to deactivate inappropriate meanings while low proficiency learners may be slower and less effective in using the sentence context cues needed for disambiguation. Therefore, it has been tentatively indicated that effective spreading activation of a word during reading and listening is important and helpful for learners' comprehension, and pedagogically suggested that consciously categorizing syntagmatically related words in L2 mental lexicon during teaching and learning new English words can help reconstruct lexical networks so as to correctly and quickly retrieve the words from the mental lexicon in a certain context and better understand the meaning of the whole context in reading and listening.
\end{abstract}

Keywords: Chinese EFL learners, English homonym processing, L2 mental lexicon, Syntagmatically related, Context

\section{Introduction}

Over the past thirty years there have been remarkable developments in the lexical access as researchers have variously attempted to focus on the processing of lexical ambiguities. As most researchers discover that lexical ambiguity often arises due to homonym (a word that has the same pronunciation and written form with two or more distinct and unrelated meanings), they have centered their research on homonym processing, a unique perspective, to examine the context effect on meaning activation and selection. They found that although homonym has several unrelated meanings, learners can select the appropriate meaning according to a certain context. Thus, the cognitive mechanism hidden behind this phenomenon arouses the interests of an increasing number of psycholinguists and has become an important area for the investigation of context in word recognition.

In order to evaluate what factors (context, meaning frequency, SOA (Stimulus Onset Asymmetry), language 
proficiency) influence learners' homonym processing, many different experimental tasks (phoneme-monitoring paradigm, eye-movement techniques and the primed lexical decision task) have been conducted. Findings suggest that the homonym processing in L1 depends on two main factors: the relative frequency of word meanings and constrains imposed by the context. Nevertheless, it still remains a controversial issue, as three different kinds of models have been proposed. They are exhaustive access model, the selective access model and the ordered access model. Moreover, studies in L2 (Elston-Guttler \& Friederici 2004; Frenck-Mestre \& Prince, 1997; Love, Maas, \& Swinney, 2003) only began a decade ago and have obtained limited results on the processing of lexical ambiguity within a non-native language. Therefore, those mixed findings call for additional studies on the influence of sentence context on homonym processing in relation to their language proficiency and organization of their mental lexicon and to specify the factors that might influence the learners' homonym processing.

In the present study, we investigate the Chinese EFL learners' homonym processing in sentential context by taking subjects' language proficiency and storage mode of mental lexicon into consideration, together with the nature of context, relative frequency of meanings, SOA conditions. If words semantically associated in mental lexicon are easily retrieved under a certain context, we then may infer that the organization of homonym in mental lexicon may be a factor that influences its processing in sentential context. Therefore, we pay attention to the English homonyms processing. That is to investigate if there is any correlation between Chinese EFL learners' homonym processing and their organization of L2 mental lexicon

To this end, we employed a cross-modal sentence-priming lexical decision task and word association task to examine the effect of semantic and syntactic context on the processing of two types of homonyms (same/mixed-category) to evaluate the extent to which syntactic aspects affect homonym processing.

\section{Brief review of related literature}

\subsection{L2 mental lexicon and its word associations}

Psycholinguists (Carrol, 2000:102) define the representation of the words in the permanent memory as mental lexicon. Carrol believes that the mental lexicon contains a wide range of lexical information, including the meaning, spelling, pronunciation, and the relation with other words, and related information of its each entry. In short, L2 mental lexicon is a container of the L2 lexical knowledge in a speaker's mind, which has a large storing capacity, including words and expressions of the language.

A word in a well-organized mental lexicon can be retrieved faster. Since the storage mode of the L2 mental lexicon can easily affect the retrieval of the words, the reorganization of L2 mental lexicon is crucial to speech comprehension. According to the previous researches (Li, 2009; Zhang, 2010; Guo, 2010), there are four main types of word associations (non-related, phonological, syntagmatic and paradigmatic associations) of L2 mental lexicon are summarized in Table 1. Among them, syntagmatic associations refer to the relationship between two words which can go together and be meaningful no matter what kind of part of speech, for example, in "the black cat" the adjective "black" modifies the noun "cat". Paradigmatic associations describe the relationship between the meanings of the words, such as synonymy, antonymy, and hyponymy.

The process of reorganization of the L2 mental lexicon is dynamic which mainly involves two procedures: categorizing the old lexical knowledge in terms of semantic connections and matching newly-learned words with pre-existing knowledge so as to build lexical networks in the mental lexicon. Previous research (Li, 2009) found that there is a correlation between the organization mode of the L2 mental lexicon and L2 learners' language proficiency. With the improvement of L2 learners' language proficiency, words stored in L2 mental lexicon undergo a developmental shift from initially being phonologically connected to being gradually semantically associated.

\subsection{Lexical access}

According to Tabossi (1991), the lexical access refers to retrieval of the semantic information related to a word when the word is recognized. That is to say, the term "lexical access" focuses on meaning retrieval. Several factors have been found to affect lexical access, such as frequency, word length, context, recency, lexicality, semanticity, and imageability effect.

\subsection{Experimental tasks for researching on lexical ambiguity processing}

Different kinds of experimental tasks have been conducted to manipulate the presence and the difficulty of lexical access, such as phoneme-monitoring paradigm, eye-movement techniques and the primed lexical decision task. These tasks have provided the experimenters with a detailed understanding of the potential factors (frequency, repetition, semantic relatedness and phonological relatedness) that might affect the lexical access.

Many findings of five models have come from priming studies. The priming procedure is implemented in several ways, depending on the method of presentation of the context, the location of the ambiguity in the sentence and 
the task performed on the target. Many researchers followed the cross-modal procedure, in which subjects hear a sentence with a visual target presented. Moreover, the literature of lexical ambiguity processing reveals that lexical processing is fast, thus it is of fundamental importance that the process of access be tapped on-line. According to Tabossi \& Sbisa (2002), the best paradigm is capturing access processes on-line, giving as much information as possible on the availability of the different meanings of an ambiguous word and not allowing participants to develop response strategies. By comparison, we choose cross-model sentence-priming lexical decision task for our study.

\subsection{Previous studies of homonym processing in $L 1$ and $L 2$}

In the psycholinguistic literature, studies of the processing of lexical ambiguity in L1 and L2 context have received much attention.

In L1 context, previous studies on processing lexical ambiguity have focused on two main factors: context and meaning frequency. Five models on homonym processing have been proposed, namely, the exhaustive access model, the selective access model, the ordered access model, the reordered access model and the context-sensitive model. The mixed results of all the processing studies seem to indicate that the nature of context, relative frequency of meanings and time course can affect the processing of lexical ambiguity.

With further research on this area, linguists turned to pay attention to the unselected meaning of the ambiguous words. Several studies (Chwilla \& Kolk, 2003) considered that the unselected meanings were inhibited by the mechanism of suppression that plays an important role in meaning selection. More than a decade ago, researchers began to use different methods to explore what factors can influence the homonym processing in L2. Only a limited number of studies (Elston-Guttler \& Friederici 2004; Frenck-Mestre \& Prince, 1997; Love, Maas, $\&$ Swinney, 2003) have addressed the processing of lexical ambiguity within a non-native language explicitly.

\subsection{Summary}

From the review of the theories of the previous studies in processing of lexical ambiguity both in L1 and L2, some useful results can be concluded as follows: first, lexical ambiguity processing is the activation of the contextually appropriate meanings and suppression of the contextual inappropriate meanings; second, the nature of context, meaning frequency and time course (SOA conditions) are the main factors that can influence the processing; third, high proficiency non-native learners can achieve native-like processing of homonym in sentence context at the early stage, but the native seem to have a more efficient suppression mechanism at the late stage. However, most studies chose ESL learners as their participants and few researches have been conducted with EFL learners being the subjects, especially on the different performance of English major and non-English major in terms of their language proficiency. In addition, the subjects' storage mode of the mental lexicon has not been taken into consideration. Therefore, in the present study we investigate the Chinese EFL learners' homonym processing in sentential context by taking the nature of context, relative frequency of meanings, SOA conditions, language proficiency and storage mode of mental lexicon into consideration. We use $\mathrm{RT}$ and PC as dependent variable and introduced contexts (same-/mixed category) to evaluate whether syntactic aspects affect homonym processing.

\section{Research Design}

\subsection{Research questions and hypotheses}

Our review of literature led us to enquire the following research question:

What is the correlation between the learners' English homonym processing patterns and their organization of homonyms in mental lexicon?

In response to the research question and on the basis of the analysis of various L1 theories of ambiguity processing discussed in the literature review and on sentence processing studies in L2, the following hypotheses may be put forward.

Hypothesis A: There is a positive correlation between learners' organization of L2 mental lexicon and their performance on English homonym processing.

Hypothesis B: Syntagmatically related organization of $L 2$ mental lexicon can be helpful for efficient processing of English homonyms.

\subsection{Research variables}

The present study compared the homonym processing patterns within sentences by Chinese EFL learners of English majors and non-English majors. We used both RT (reaction time) and PC (percent correct) as dependent variables, Group, Relatedness and Context and Same/Mixed context (target corresponding to a same-category noun-noun context versus a mixed-category none-verb context), Organization of English homonyms in L2 mental lexicon as independent variables, and both age and gender of the participants as control variables. We can see the research variables in this experiment in Figure 1. 


\subsection{Participants}

The subjects of the present study consist of 45 Chinese EFL learners who were divided into two groups, the first with two sub-groups of 15 each having 30 non-English major students who are further divided according to their language proficiency levels (as defined by the subjects' educational grade level) and the second group having 15 English majors. That is, thirty non-English majors from USTC are divided into "relatively low English proficiency" sub-group and "high proficiency" sub-group. Fifteen graduates of English-major students served as the second group in the same experiment.

\subsection{Instruments}

In the present study, the cross-modal sentence-priming lexical decision task and word association task were employed to explore how the Chinese EFL learners with different English proficiency select the contextually appropriate meaning of the homonyms in sentential context and try to investigate what factors influence English homonym processing by using software E-prime 2.0 and questionnaire. In order to ensure the validity and reliability of the selected materials, 30 English homonyms and 60 related sentences used in the present study were chosen from the paper Native and L2 processing of homonyms in sentential context written by Kerrie E. et al published in Journal of Memory and Language in 2005. All the English homonyms had to be sentence-final, all targets were designed to reflect the contextually appropriate or inappropriate meaning and the sentence contexts were constructed to be biased toward either the first or the second meaning of the English homonyms so as to make sure sentence length, frequency and the length of critical primes and targets are valid to our study. Moreover, in order to avoid the Chinese EFL learners' misunderstanding of the unfamiliar English homonyms, we give the participants a questionnaire before the formal experiment.

\subsection{Procedures}

Subjects completed the two tasks respectively. Participants were first instructed to read the beginning of a sentence (all but the last word) and to press the space key on the keyboard when ready to continue. The sentence then disappeared, and the single word prime was presented for $500 \mathrm{~ms}$, and then disappeared. The target then appeared at the same point on the screen and the participant had to press the key " $y$ " if the target was a word semantically or associatively related to the prime and the key " $\mathrm{n}$ " if it was not a word. The target disappeared as soon as the subject responded. For example:

The little boy liked his (subject presses space key when ready)

present (presented $500 \mathrm{~ms}$ )

gift (subject makes lexical decision)

The second task was to find the correlation between the learners' disambiguation and their organization of homonyms in mental lexicon by using the verbal questionnaire which included 30 English homonyms used in the first task. First, the experimenter distributed the questionnaire to each participant, and then each participant was asked to write down one word that occurred to their mind as soon as they saw the word on the questionnaire; finally, the experiment data were collected.

\subsection{Data collection and analysis}

The participants' reactions to the target words during cross-modal sentence-priming lexical decision task and the answers to the questionnaire during the word association task were recorded. Mean RTs (reaction time) for correct responses and percentage correct were calculated for each subject. Some data would be removed from analysis, such as responses shorter than $200 \mathrm{~ms}$ and longer than the $3000 \mathrm{~ms}$ cut-off. These RTs and PC data then subjected to the respective by-participant and by-item ANOVA and SPSS 16.0 for the final results.

Data collected after word association task were classified into one of the four types: phonological, syntagmatic, paradigmatic and others, according to its relationship to the prompt homonym, and then the number of each type is calculated in terms of three groups and entered the SPSS 16.0.

\section{Results and Discussion}

\subsection{Findings of the WAT (Word Association Task)}

In the word association task in which subjects had to give a single response to each of the $30 \mathrm{prompt}$ words, the responses made by each group of fifteen participants added up to 450 in total. Therefore all 1350 responses made by three groups were analyzed in terms of association type and group category. They are presented in Table 2 .

The results (Figure 2) show that there is a correlation between the organization mode of the L2 mental lexicon and L2 learners' language proficiency. By comparing the responses of the three groups, we can find that there is a general tendency of an obvious decrease in the number of non-related, phonological and syntagmatic associations with an increase of proficiency levels, respectively from $12 \%$ to $10 \%$ to 0 for non-related associations, from $27 \% / 29 \%$ to $6 \%$ for phonological associations and from $29 \% / 15 \%$ to $21 \%$. However, an 
increase occurs to paradigmatic associations, respectively from $30 \%$ to $46 \%$ to $73 \%$.

By comparing the responses of the two sub-groups of Non-English major, we can find that there is some differences between them, especially for the paradigmatically and syntagmatically related associations. There is a general tendency of an obvious decrease in the number of paradigmatic associations with an increase educational grade level, respectively from $29 \%$ to $15 \%$ and an increase occurs to syntagmatic associations from $30 \%$ to $46 \%$. However, the ratios of the non-related and phonologically related associations are similar to each other, from $12 \%$ to $10 \%$ and from $27 \%$ to $29 \%$.

\subsection{Findings of the Cross-modal Sentence-priming Lexical Decision Task}

In the cross-modal sentence-priming lexical decision task in which subjects had to give a response to each prime of the given sentences, the responses (reaction time and the percent correct) made by each group of ten participants added up to 1600 in total. Therefore all 4800 responses made by three groups were analyzed in terms of association type and group category, presented in Table 3.

The results (Figure 3) show that there is a positive correlation between the learners' language proficiency and their efficiency in homonym processing. That is, the higher the L2 learners' language proficiency is, the faster and more correctly they process the homonyms.

\subsection{Discussion}

The results of the word association task showed that English major learners' L2 mental lexicons have more syntagmatically and paradigmatically related words than non-English major learners' and the results of the cross-modal sentence-priming lexical decision task reveals that English major learners can process English homonyms more correctly and quickly in the sentence context. These findings further suggest that there is a positive correlation between learners' organization of L2 mental lexicon and their performance on English homonym processing. That is to say, words that are more syntagmatically and paradigmatically related in Chinese EFL learners' L2 mental lexicon, the more efficient processing of English homonyms they will have.

\subsubsection{The organization of English homonyms in L2 mental lexicon}

The organization of English-major learners' L2 mental lexicon differs from the organization of non-English major learners'. Generally speaking, English-major learners have better-organized mental lexicon than non-English major learners'. For the English-major learners, the words stored in their mind are all related to each other, only $6 \%$ of the words are phonologically-related, the rest of the words are semantically or syntactically related. But for the non-English major learners, about $12 \%$ of the words are not related, $28 \%$ of the words are phonologically related, $60 \%$ of the words are semantically or syntactically related.

By taking their performance in processing English homonyms into consideration, learners of English major have better performance than non-English majors. Thus, more words that are syntagmatically and paradigmatically related in L2 mental lexicon organization can be considered as a better mode. This mode can help learners predict other words that are in a syntagmatically related lexical system when they process an English homonym. In contrast, English-major learners may use sufficient contextual cues (semantic and syntactic information) to comprehend a certain context while non-English-major learners may be slower and less effective in using the sentence context cues needed for comprehension.

4.3.2 The correlation between learners' organization of English homonyms in L2 mental lexicon and their performances on English homonym processing

From the results (Figure 5) of the cross-modal sentence-priming lexical decision task, we can find English-major learners can more correctly and quickly retrieve the right meanings of the sentences than non-English major learners. By taking the organization of mental lexicon into consideration, the results showed that there is a positive correlation between learners' organization of L2 mental lexicon and their performance on English homonym processing (Figure 6).

Thus, we can get a conclusion that words that are more syntagmatically and paradigmatically related stored in Chinese EFL learners' L2 mental lexicon, the more effective English homonym processing the learners' have.

Additionally, inferential statistic analysis indicates that learners whose L2 mental lexicon is more syntagmatically related can process the English homonym more effectively. They can use contextual cues (semantic and syntactic information) to deactivate inappropriate meanings while low proficiency learners may be slower and less effective in using the sentence context cues needed for disambiguation.

\subsection{Discussion in relation to the results of the previous studies}

Previous research (Li, 2009) found that there is a correlation between the organization of the L2 mental lexicon and L2 learners' language proficiency. With the improvement of L2 learners' language proficiency, words stored in L2 mental lexicon undergo a developmental shift from initially being phonologically connected to being 
gradually semantically associated. In our study, we found that non-English major learners with high proficiency have better-organized mental lexicon than relatively low proficiency learners of non-English major and English-major learners have better-organized mental lexicon than non-English major learners. To a certain extent, our findings indicate the previous studies that there is a correlation between the organization of the L2 mental lexicon and L2 learners' language proficiency is reasonable.

Besides, studies of the processing of lexical ambiguity in L1 and L2 context suggest that the homonym processing depends on two main factors: the relative frequency of word meanings and constrains imposed by the context. In our study, we confirm that context cues are helpful for the processing of English homonyms. Moreover, context cues come from the effective spreading activation of a word. Thus, organization of the words stored in mind is crucial for effectively processing of the English homonyms.

\subsection{Generalization}

From the study, we found there is a positive correlation between learners' organization of English homonyms in L2 mental lexicon and their performances on English homonym processing. Therefore, it has been tentatively implied that effective spreading activation of a word during reading and listening is important to understand a certain context. Thus, consciously categorizing syntagmatically related and paradigmatically related words in L2 mental lexicon during teaching and learning new English words can build better-organized lexical networks so as to correctly and quickly retrieve the words from the mental lexicon in a certain context and better understand the meaning of the whole context in reading and listening.

\section{Summary \& Pedagogical Implication}

By doing the experiments, we can find the correlation between learners' organization of L2 mental lexicon and their performance on homonym processing. To further interpret the findings, the organization of the learners' mental lexicon might explain the difference. English majors benefit more from the context cues than non-English majors and can suppress the contextually inappropriate meanings more effectively, whereas the non-English major learners cannot. The findings implied that the "message" around a word is important, thus it is pedagogically suggested that teachers may help students consciously categorize words in terms of meaning and build better-organized lexical networks to achieve economic and efficient processing of lexical ambiguity. That is, teachers should help students construct semantic fields under various semantic relations by not only teaching pronunciation and meanings of a word, but also explaining its semantic relations, connotation and collocations

The present study could not possibly embrace all the factors concerned. One limitation of the study was that it only investigates the homonym processing in sentential context. And what are the learners' homonym processing patterns in discourse context? Further investigation is called for in this area.

Despite the limitations present in our division of homonyms as same or mixed category, our findings are expected to shed light on the potentially different mechanisms involved in Chinese EFL learners' homonym processing in sentential context. This research is significant in that it provides implications for the construction of lexical access theories and the theories of organization of mental lexicon and sheds lights on L2 lexical acquisition.

\section{References}

De Bruijn, E.R.A., Dijkstra, T., Chwilla, D. J., \& Schriefers, H.J. (2001). Language context effects on interlingual homograph recognition: Evidence from event-related potentials and response times in semantic priming. Bilingualism: language and Cognition, 4, 155-168. doi:10.1017/S1366728901000256, http://dx.doi.org/10.1017/S1366728901000256

Elston-Güttler, K. \& A. Friederici. (2005). Native and L2 processing of homonyms in sentential context. Journal of Memory and Language, 52: 256-283.

Fodor, J. A. (1983). The modularity of mind. Cambridge, MA: MIT Press.

Forster, K. I., \& Bednall, E. S. (1976). Terminating and exhaustive search in lexical access. Memory \& Cognition, 4, 53-61. doi:10.3758/BF03213255, http://dx.doi.org/10.3758/BF03213255

Frenck-Mestre, C. \& P. Prince. (1997). Second language autonomy. Journal of Memory and Language, 37: 481-505. doi:10.1006/jmla.1997.2526, http://dx.doi.org/10.1006/jmla.1997.2526

Guo, Changhong. (2010). The application of the semantic field theory in college English vocabulary instruction. Chinese Journal of Applied Linguistics (Bimonthly). 33(3), 50-62.

Kotz, S.A., \& Elston-Güttler, K.E. (2004). The role of proficiency on processing categorical and associative information in the L2 as revealed by reaction times and eventrelated brain potentials. Journal of Neurolinguistics, 17, 215-235. doi:10.1016/S0911-6044(03)00058-7, http://dx.doi.org/10.1016/S0911-6044(03)00058-7

Love, T., Maas, E., \& Swinney, D. (2003). The influence of language exposure on lexical and syntactic language 
processing. Experimental Psychology, 50, 204-216. doi:10.1026//1617-3169.50.3.204, http://dx.doi.org/10.1026//1617-3169.50.3.204

Martin, C., Vu, H., Kellas, G., \& Metcalf, K. (1999). Strength of discourse context as a determinant of the subordinate bias effect. The Quarterly Journal of Experimental Psychology, 52, 813-839. doi:10.1080/027249899390819, http://dx.doi.org/10.1080/027249899390819

McClelland, J. L. (1987). The case for interactionism in language processing. In M. Coltheart (Ed.), Attention and performance XII: The psychology of reading. Mahwah, NJ: Erlbaum.

PauI ST, Kellas G, et a1. (1992). The influence of contextual features on the activation of ambiguous word meaning. Journal of Experiment psychology: Learning, Memory and Cognition, 18, $703-717$. doi:10.1037/0278-7393.18.4.703, http://dx.doi.org/10.1037/0278-7393.18.4.703

Rayner, K., Binder, K. S., \& Duffy, S. A. (1999). Contextual strength and the subordinate bias effect: Comment on Martin, Vu, Kellas, and Metcalf. The Quarterly Journal of Experimental Psychology, 52, 841-852. doi:10.1080/027249899390828, http://dx.doi.org/10.1080/027249899390828

Simpson G B, \& Krueger MA. (1991). Selective access of homograph meanings in sentence context. Journal of Memory and Language, 30, 627-643. doi:10.1016/0749-596X(91)90029-J, http://dx.doi.org/10.1016/0749-596X(91)90029-J

Simpson, G. B. (1984). Lexical ambiguity and its role in models of word recognition. Psychological Bulletin, 96(2), 316-340. doi:10.1037/0033-2909.96.2.316, http://dx.doi.org/10.1037/0033-2909.96.2.316

Simpson, G. B. (1994). Context and the processing of ambiguous words. In M. A. Gernsbacher (Ed.), Handbook of psycholinguistics. San Diego: Academic Press.

Simpson, G. B., \& Kang, H. (1994). Inhibitory processes in the recognition of homograph meanings. In D. Dagenbach \& T. H. Carr (Eds.), Inhibitory processes in attention, memory and language. San Diego, CA: Academic Press.

Sun, Lan \& Li, Xiaoli. (2009). A study of the organization of L2 mental lexicon through word association tests. Teaching English in China-CELEA Journal. 32(6), 80-87.

Swinney, D. A. (1991). The resolution of indeterminacy during language comprehension: Perspectives on modularity in lexical, structural and pragmatic process. In G. B. Simpson (Ed.), Understanding word and sentence. Amsterdam: Elsevier.

Tabossi, P. (1988). Accessing lexical ambiguity in different types of sentential contexts. Journal of Memory and Language, 27, 324-340. doi:10.1016/0749-596X(88)90058-7, http://dx.doi.org/10.1016/0749-596X(88)90058-7

Zhao, Chen \& Dong, Yanping. (2009). The Resolution of English Lexical Ambiguity by Chinese EFL Learners in Sentential Context. Foreign Language Teaching and Research, 41(3).

Zhao, Cuilian. (2005). Mental representation of polysemy development model: Based on the experimental study of Chinese EFL learners. Foreign Language Teaching and Research, 37(4).

Zhao, Ping. (2010). Contrastive study on Chinese EFL learners' Mental Lexicon Organizaiton. Foreign Language Teaching and Research, 42(1).

\section{Appendix}

Primes with Sentential Contexts and Their Targets used in cross-modal sentence-priming lexical decision task

(The words in brackets are unrelated primes; words in the second column are targets for dominant primes and words in the third column are targets for the subordinate primes)

Sentences Ending in Ambiguous Primes (Homonym) Target

Homonyms used in same-category contexts

(a)He went to hospital for a regular check (visit)

(b)To pay the bill his mother wrote check (contract)

(a)Mary liked the intonation of the sentence (manager)

(b)The judge announced the sentence (victory)

(a)John wrote a long letter (poem)

(b)The children learned each letter (item)

(a)The young man started a company (fight) examination

cash

word

crime

mail

alphabet

business 
(b)The old woman needed company (milk)

$$
\begin{gathered}
\text { friend } \\
\text { summer } \\
\text { fountain } \\
\text { tale } \\
\text { floor } \\
\text { follower } \\
\text { cool } \\
\text { money } \\
\text { river } \\
\text { Jelly } \\
\text { traffic } \\
\text { lenses } \\
\text { cups }
\end{gathered}
$$

(a)He enjoyed traveling in the spring (holiday)

(b)The tourists came to see the spring (church)

(a)The children loved telling the story (teacher)

(b)He reached the fourth story (street)

(a)The singer had a lot of fans (flag)

(b)The room was kept fresh by the fan (ice)

(a)The business men waited by the bank (room)

(b)They saw a bird along the bank (way)

(b) Jill was in an awful jam (drama).

(a) To read Dave needed his glasses (journal).

(b) The couple had a bunch of glasses (daisies).

Homonyms used in mixed-category contexts

(a) The woman says that she will (does).

(b) The old man prepared his will (bed).

(a)John climbed a tree and kept watch (silence)

won't

(b)The boy wore a new watch (shirt)

testament

look

clock

(a) The idea was hard to express (reject).

(b) Every day he took the express (paper).

convey

train

(a) Her dream was to fly (drive).

sky

bug

(b) The farmer killed the fly(cow).

(a) He lifted the heavy box (stone).

(b) The man learned to box (sing).

(a) John needed some change (water).

(b) His friends asked him to change (leave).

(a) The woman broke her arm (door).

(b) The extremist was dangerous to arm (catch).

cardboard

fight

coins

alter

shoulder

weapon

grizzly

carry

read

(b) The music was too loud to bear (appreciate).

reserve

(b) The table was difficult to book (move).

dry

(a) They drove through the desert (forest).

depart

\section{Questionnaire}

Hello, Everyone! Welcome to the investigation of the organization of English words in L2 mental lexicon. This survey is anonymous, and your answers are only for research, thank you for your cooperation!

Here are 30 words, and you are required to write down one word that occurred to their mind as soon as you saw each word on the questionnaire which can be voice-related, semantically related or unrelated words

$\begin{array}{ll}\text { 1. } & \text { check } \\ \text { 2. } & \text { sentence } \\ \text { 3. } & \text { letter } \\ \text { 4. } & \text { company } \\ \text { 5. } & \text { spring } \\ \text { 6. } & \text { story } \\ \text { 7. } & \text { present } \\ \text { 8. } & \text { yard } \\ \text { 9. } & \text { case } \\ \text { 10. } & \text { fan }\end{array}$

$\begin{array}{ll}\text { 11. } & \text { bank } \\ \text { 12. } & \text { jam } \\ \text { 13. } & \text { glass } \\ \text { 14. } & \text { ruler } \\ \text { 15. } & \text { plant } \\ \text { 16. } & \text { will } \\ \text { 17. } & \text { watch } \\ \text { 18. } & \text { express } \\ \text { 19. } & \text { turn } \\ \text { 20. } & \text { fly }\end{array}$

21. strike

22. box

23. change

24. match

25. means

26. stick

27. arm

28. bear

29. book

30. desert 
Table 1. Types of word association

\begin{tabular}{|l|l|l|}
\hline Types of association & Classificatory criteria & Examples \\
\hline Phonological-related & similar pronunciations & $\begin{array}{l}\text { will-well; } \\
\text { desert-dessert }\end{array}$ \\
\hline Syntagmatic-related & $\begin{array}{l}\text { The components in a phrase are not } \\
\text { only grammatically related, but also } \\
\text { semantically related (collocation, } \\
\text { polysemy, metaphorical meaning } \\
\text { etc.) }\end{array}$ & $\begin{array}{l}\text { plant-tree; } \\
\text { story-funn; } \\
\text { fly-sky; } \\
\text { fan-zealous; } \\
\text { letter-pen; } \\
\text { desert-sand; } \\
\text { bank-money; } \\
\text { desert-dry }\end{array}$ \\
\hline Paradigmatic-related & $\begin{array}{l}\text { meaning-related in semantic field } \\
\text { (synonymy, antonymy, hyponymy } \\
\text { etc) }\end{array}$ & $\begin{array}{l}\text { spring-summer; } \\
\text { ruler-rule; } \\
\text { letter-word; } \\
\text { express-expression; } \\
\text { arm-leg }\end{array}$ \\
\hline Others (non-related etc.) & everything else & \\
\hline
\end{tabular}

Table 2. Distribution of response types (WAT)

\begin{tabular}{|l|l|l|l|l|l|}
\hline & $\begin{array}{l}\text { Others } \\
(\%)\end{array}$ & Phonological (\%) & Syntagmatic (\%) & Paradigmatic (\%) & Total (\%) \\
\hline $\begin{array}{l}\text { English major } \\
\text { (graduate) }\end{array}$ & $0 / 0$ & $2 / 6$ & $6 / 21$ & $22 / 73$ & $30 / 100$ \\
\hline $\begin{array}{l}\text { Non-English major } \\
\text { (graduate) }\end{array}$ & $3 / 10$ & $9 / 29$ & $4 / 15$ & $14 / 46$ & $30 / 100$ \\
\hline $\begin{array}{l}\text { Non-English major } \\
\text { (undergraduate) }\end{array}$ & $4 / 12$ & $8 / 27$ & $9 / 29$ & $9 / 30$ & $30 / 100$ \\
\hline
\end{tabular}

Table 3. Distribution of response (Lexical Decision Task)

\begin{tabular}{|l|l|l|l|}
\hline Group & RT(ms) & PC (\%) & EC (\%) \\
\hline English major & 1342 & 90 & 10 \\
\hline Non-English major (graduate) & 1535 & 78 & 22 \\
\hline Non-English major (undergraduate) & 1514 & 82 & 18 \\
\hline
\end{tabular}

\begin{tabular}{|c|c|}
\hline $\begin{array}{l}\text { FACTORS (Independent Variables) } \\
\text { 1. Relatedness (targets preceded by a related unrelated prime) } \\
\text { 2. Group \{learners of English major and non-English major (high and } \\
\text { 3. Approficiency)\} } \\
\text { 4. Same-/Mixed-Context (noun-noun noun-verb) } \\
\text { 5. Organization of English homonyms in L2 mental lexicon }\end{array}$ & $\begin{array}{l}\text { RESULTS } \\
\text { (Dependent Variables) } \\
\text { English Homonym } \\
\text { Processing by Chinese } \\
\text { EFL learners } \\
1 \text {. RT } \\
\text { (Reaction Time) } \\
2 \text { PC } \\
\text { (Percent Correct) }\end{array}$ \\
\hline $\begin{array}{l}\text { (Control Variables) } \\
\begin{array}{ll}\text { 1. Age } & \text { 2. Gender }\end{array}\end{array}$ & \\
\hline
\end{tabular}

Figure 1. Research Variables of the Experiments

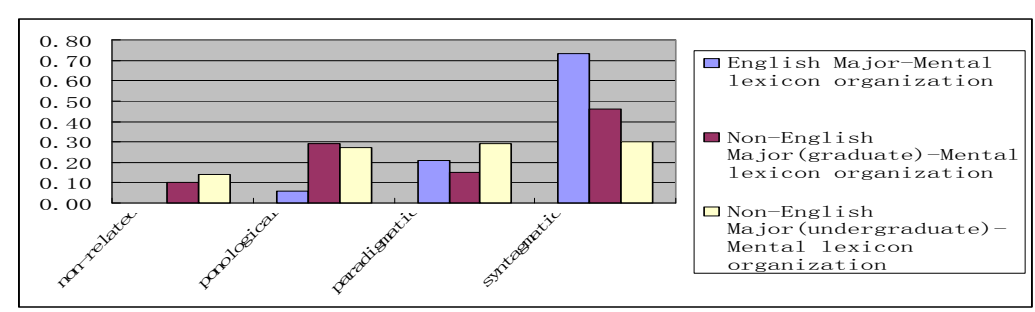

Figure 2. Comparison of distribution of response types in word association task for English majors and non-English majors 


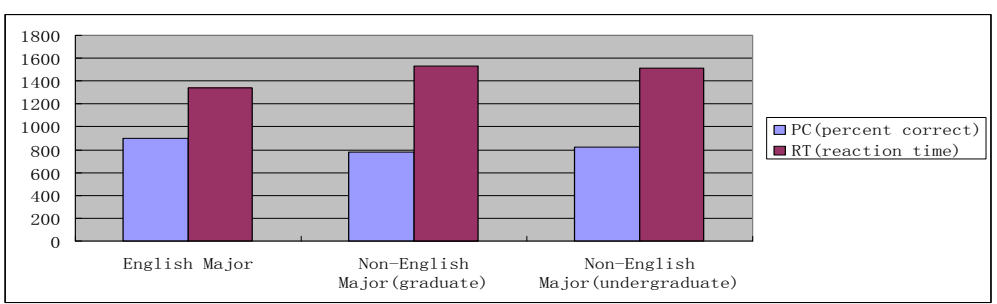

Figure 3. Comparison of distribution of response in lexical decision task for English majors and non-English majors (numbers of PC in the Figure are 1000 times as many as the original ones for easier comparison)
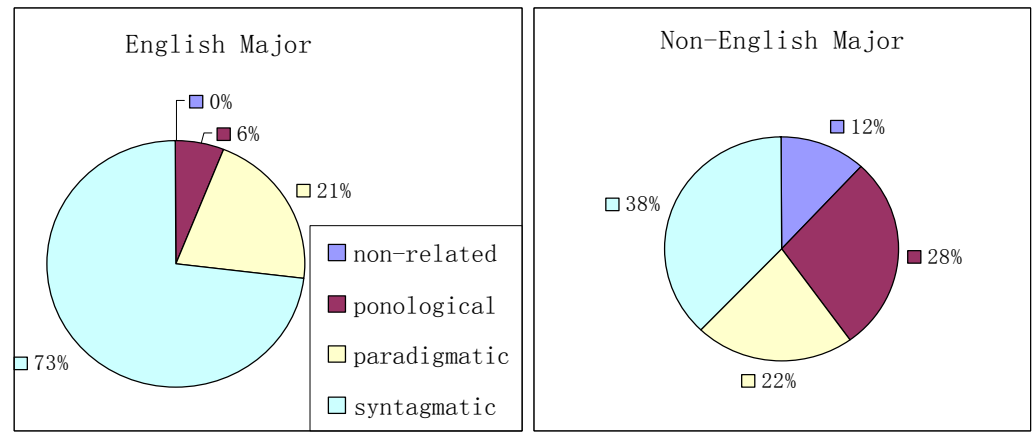

Figure 4. Comparison of the organization of English homonyms in L2 mental lexicon for English majors and non-English majors

\begin{tabular}{|c|c|c|c|c|c|c|c|c|c|}
\hline \multicolumn{10}{|c|}{ Correlations } \\
\hline & & group & gender & RT & $\mathrm{PC}$ & nonrelated & phonological & paradigmatic & syntagmatic \\
\hline \multirow[t]{2}{*}{ group } & Pearson Correlation & 1 & $-.690^{\circ}$ & $.533^{\circ}$ & $-.558^{\prime \prime}$ & $.694^{\prime \prime}$ & $.642^{\circ}$ & .142 & $-.814^{\prime \prime}$ \\
\hline & Sig. (2-tailed) & & .001 & .013 & .009 & .000 & .002 & .538 & .000 \\
\hline \multirow[t]{2}{*}{ gender } & Pearson Correlation & $-.690^{\prime \prime}$ & 1 & $-.615^{\prime \prime}$ & $.518^{\circ}$ & $-.816^{\prime \prime}$ & $-.583^{\prime \prime}$ & -.018 & $.761^{\prime \prime}$ \\
\hline & Sig. (2-tailed) & .001 & & .003 & .016 & .000 & .006 & .939 & .000 \\
\hline \multirow[t]{2}{*}{ RT } & Pearson Correlation & $.533^{\circ}$ & $-.615^{\prime \prime}$ & 1 & $-.804^{\prime \prime}$ & $.659^{\prime \prime}$ & $.595^{*}$ & -.064 & $-.676^{\prime \prime}$ \\
\hline & Sig. (2-tailed) & .013 & .003 & & .000 & .001 & .004 & .783 & .001 \\
\hline \multirow[t]{2}{*}{$\mathrm{PC}$} & Pearson Correlation & $-.558^{\prime \prime}$ & $.518^{\circ}$ & $-.804^{\prime \prime}$ & 1 & $-.733^{\prime \prime}$ & $-.671^{\prime \prime}$ & 251 & $.684^{\prime \prime}$ \\
\hline & Sig. (2-tailed) & .009 & .016 & .000 & & .000 & .001 & .272 & .001 \\
\hline \multirow[t]{2}{*}{ nonrelated } & Pearson Correlation & $.694^{\prime \prime}$ & $-.816^{*}$ & $.659^{\prime \prime}$ & $-.733^{*}$ & 1 & $.724^{\circ}$ & -.134 & $-.877^{\prime \prime}$ \\
\hline & Sig. (2-tailed) & .000 & .000 & .001 & .000 & & .000 & .564 & .000 \\
\hline \multirow[t]{2}{*}{ phonological } & Pearson Correlation & $.642^{\prime \prime}$ & $-.583^{*}$ & $.595^{*}$ & $-.671^{*}$ & $.724^{\prime \prime}$ & 1 & $-.440^{\circ}$ & $-.849^{\prime \prime}$ \\
\hline & Sig. (2-tailed) & .002 & .006 & .004 & .001 & .000 & & .046 & .000 \\
\hline \multirow[t]{2}{*}{ paradigmatic } & Pearson Correlation & .142 & -.018 & -.064 & .251 & -.134 & $-.440^{\circ}$ & 1 & -.043 \\
\hline & Sig. (2-tailed) & 538 & 939 & .783 & 272 & .564 & .046 & & .855 \\
\hline \multirow[t]{2}{*}{ syntagmatic } & Pearson Correlation & $-.814^{\prime \prime}$ & $761{ }^{\prime \prime}$ & $-.676^{\prime \prime}$ & $.684 "$ & $-.877^{\prime \prime}$ & $-.849^{\prime \prime}$ & -.043 & 1 \\
\hline & Sig. (2-tailed) & .000 & .000 & .001 & .001 & .000 & .000 & .855 & \\
\hline
\end{tabular}

*. Correlation is significant at the 0.01 level (2-tailed)

*. Correlation is significant at the 0.05 level (2-tailed).

Figure 5. The correlation between learners' organization of English homonyms in L2 mental lexicon and their performances on English homonym processing

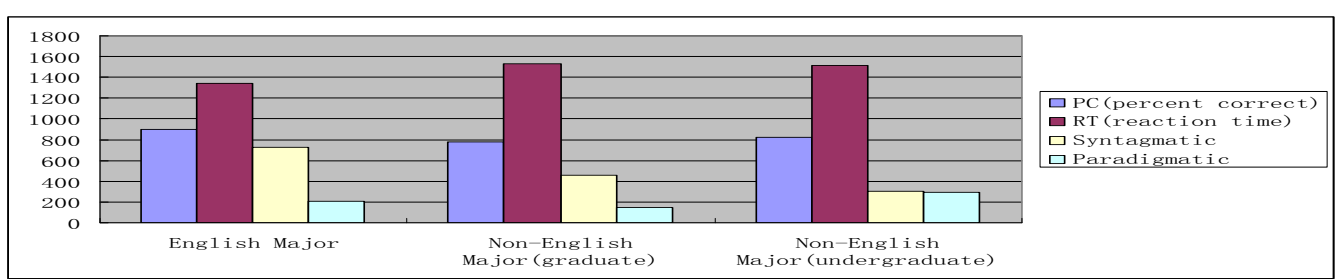

Figure 6. The correlation between learners' organization of English homonyms in L2 mental lexicon and their performances on English homonym processing (numbers of PC in the Figure are 1000 times as many as the original ones for easier comparison) 